\title{
Análise microbiológica do soro fisiológico utilizado no tratamento endodôntico
}

\section{Microbiological analysis of sterile saline solution used in endodontic treatment}

\author{
Giselle Priscilla Cruz Abi-Rached" \\ Geovânia Caldas Almeida** \\ Alexandre Augusto Zaia ${ }^{* * *}$ \\ Caio Cezar Randi Ferraz"** \\ José Flávio Affonso de Almeida*** \\ Brenda Paula Figueiredo de Almeida Gomes ${ }^{* * * *}$
}

\section{Resumo}

Objetivo: analisar a contaminação do soro fisiológico (SF) utilizado como substância irrigadora no tratamento endodôntico (TE). Materiais e método: amostras de 1 $\mathrm{mL}$ de soro fisiológico foram coletadas em tubos tipo Eppendorf. Vinte coletas microbiológicas foram realizadas em seis diferentes situações: Grupo I (GI) - logo após a abertura da embalagem de SF; Grupo II (G II) - após verter o soro na cuba endodôntica; Grupo III (G III) - no momento do $1^{\circ}$ preenchimento da seringa irrigadora; Grupo IV (G IV) - do SF ainda contido na embalagem ao final do tratamento; Grupo $V(G V)$ - do remanescente de SF da cuba endodôntica após o TE; e Grupo VI (G VI) - da seringa irrigadora ao final do TE. Cento e vinte amostras foram processadas e incubadas, e as colônias, identificadas por meio de testes bioquímicos. Foi verificado o crescimento microbiano em $20 \%$ das coletas no G I, em 30\% no G II, 55\% no G III, $50 \%$ no G IV, 90\% no G V e 90\% no G VI. Resultados: a análise estatística feita pelos testes de Kruskal-Wallis e Dunn demonstrou contaminação mais frequente nas amostras dos Grupos V e VI em relação aos Grupos I e II $(p<0,05)$. O microrganismo mais frequentemente encontrado foi Staphylococcus spp. com 79\%. Conclusão: o soro fisiológico pode ser contaminado durante $o$ seu uso na prática endodôntica.

Palavras-chave: Remoção de contaminantes. Microbiologia. Endodontia.

\section{Introdução}

O tratamento dos canais radiculares visa a eliminar e prevenir a infecção e a reinfecção por microrganismos $^{1}$. O preparo mecânico, auxiliado pela utilização de substâncias químicas auxiliares (SQA) e irrigantes dos canais radiculares, é de grande importância na terapia endodôntica por promover a remoção de tecido pulpar e restos necróticos, microrganismos presentes, debris de dentina e smear layer ${ }^{2}$.

Tanto as substâncias químicas auxiliares quanto os agentes irrigantes desempenham papéis fundamentais na terapêutica endodôntica, sendo utilizados de modos e em momentos distintos. As substâncias químicas auxiliares desempenham ações químicas, físicas e biológicas concomitantemente à ação mecânica dos instrumentos endodônticos, podendo ser empregadas na forma líquida, em gel ou em creme ${ }^{3}$. Já os irrigantes apresentam-se apenas na forma de soluções, uma vez que a irrigação é representada por uma corrente líquida no interior da cavidade pulpar ${ }^{4}$, com o objetivo de manter em suspensão os remanescentes necróticos, restos pulpares e debris de dentina, facilitando sua remoção por meio de aspiração.

Doutoranda na área de Endodontia da Faculdade de Odontologia de Piracicaba - Universidade Estadual de Campinas (FOP/Unicamp).

Bióloga e estagiária da área de Endodontia da Faculdade de Odontologia de Piracicaba - Universidade Estadual de Campinas (FOP/Unicamp). Professor associado da área de Endodontia da Faculdade de Odontologia de Piracicaba - Universidade Estadual de Campinas (FOP/Unicamp). Professor doutor da área de Endodontia da Faculdade de Odontologia de Piracicaba - Universidade Estadual de Campinas (FOP/Unicamp). Professor titular da área de Endodontia da Faculdade de Odontologia de Piracicaba - Universidade Estadual de Campinas (FOP/Unicamp). 
A irrigação tem um papel fundamental na determinação do sucesso da terapêutica endodôntica ${ }^{5}$. Muitos estudos demonstraram que a quantidade de debris encontrados é maior em canais preparados sem irrigação ${ }^{6}$. Na técnica preconizada pela Faculdade de Odontologia de Piracicaba - Unicamp, a substância química auxiliar de escolha é a clorexidina $2 \%$ em gel por suas propriedades antimicrobianas, lubrificante, substantividade, diminuição da formação de smear layer, baixa citotoxicidade, entre outras ${ }^{7-9}$. O agente irrigador é o soro fisiológico, por promover a suspensão de partículas, favorecendo, assim, a sua remoção, e por diminuir o risco de reações químicas entre as substâncias químicas auxiliares empregadas.

De acordo com Byströn e Sundqvist ${ }^{2}$ (1981), canais preparados manualmente utilizando apenas $o$ soro fisiológico tiveram uma redução de $53,4 \%$ de células bacterianas da luz do canal. Berber et al. ${ }^{10}$ (2006), em um estudo avaliando a redução de $E$. $f a$ ecalis por meio de diferentes substâncias auxiliares e técnicas, verificaram a redução de $99 \%$ de células bacterianas também da luz do canal quando da utilização do soro fisiológico em todas as técnicas testadas. Martinho et al. ${ }^{11}$ (2010) verificaram redução de $96,27 \%$ do conteúdo endotóxico dos canais radiculares com polpa necrosada, usando irrigação com salina estéril/apirogênica e instrumentação rotatória com limas de níquel-titânio do sistema Mtwo (VDW GmbH, Munique, Alemanha).

O soro fisiológico utilizado na terapêutica endodôntica tem de ser estéril, uma vez que seu uso em condições impróprias pode servir de via de infecção ou reinfecção do sistema de canais radiculares. Entretanto, o soro pode ser contaminado pelo simples procedimento da abertura de sua embalagem, pela exposição na cuba endodôntica durante o tratamento endodôntico e durante o preenchimento de seringas irrigadoras.

O objetivo do presente estudo é avaliar e identificar a contaminação microbiológica do soro fisiológico durante o tratamento de canais radiculares.

\section{Materiais e método}

Amostras de $1 \mathrm{~mL}$ de soro fisiológico foram coletadas em condições assépticas em tubos tipo Eppendorf de 1,5 mL (Cral, São Paulo, SP, Brasil), com o auxílio de micropipeta (Nichipet, Nichiryo Co. Ltd., Tóquio, Japão), durante 20 tratamentos endodônticos realizados na Clínica de Graduação da Faculdade de Odontologia de Piracicaba, Unicamp, nas seguintes situações:

- na abertura da embalagem de soro;

- do soro dispensado inicialmente na cuba endodôntica;
- do soro presente na seringa endodôntica de irrigação no início do tratamento;

- do soro remanescente na cuba ao final do tratamento endodôntico;

- do soro presente na seringa endodôntica de irrigação no final do tratamento;

- na embalagem aberta durante todo o tratamento.

O processamento das amostras foi realizado no Laboratório de Microbiologia da disciplina de Endodontia da FOP/Unicamp.

No laboratório, cada tubo contendo a amostra foi agitado por 60 segundos no agitador tipo vortex (MA 162-MARCONI, São Paulo, SP, Brasil) para facilitar a dispersão dos microrganismos. A seguir, alíquotas de $50 \mu \mathrm{l}$ de cada amostra foram plaqueadas nos seguintes meios de cultura:

- placas de ágar MacConkey para seleção de enterobactérias, incubadas em $\mathrm{CO}_{2}$ a $37{ }^{\circ} \mathrm{C}$ por 2 dias;

- placas de ágar Sabouraud-Dextrose acrescido de $0,1 \%$ de cloranfenicol para a seleção de leveduras, incubadas a temperatura ambiente $\left( \pm 25{ }^{\circ} \mathrm{C}\right)$ por 4 dias e depois incubadas em $10 \% \mathrm{CO}_{2}$ a $37^{\circ} \mathrm{C}$ por 2 dias;

- placas contendo 5\% de sangue de carneiro + Brain Heart Infusion (BHI) ágar (Oxoid, Basingstoke, UK), aerobicamente a $37{ }^{\circ} \mathrm{C}$, por 2 dias, para permitir o crescimento de microrganismos facultativos.

Após a incubação, cada placa foi examinada e os diferentes tipos de colônia foram subcultivados em placas de $\mathrm{BHI}+5 \%$ de sangue de carneiro desfibrinado recém-preparadas. As colônias foram selecionadas para a identificação inicial através das diferentes aparências nos meios ricos e seletivos. O reconhecimento morfológico das colônias foi feito de acordo com: tamanho, cor, forma, elevação, borda, superfície, textura, consistência, opacidade. As colônias puras foram inicialmente identificadas pela morfologia da coloração de Gram, requerimentos gasosos e habilidades de produzir catalase. A identificação das espécies foi realizada por meio dos testes bioquímicos padronizados, apropriados para identificação de cada espécie, como descrito a seguir.

\section{Identificação microbiana}

Os seguintes kits bioquímicos padronizados foram utilizados para a especificação primária dos microrganismos isolados:

- Rapid ID 32A (BioMérieux SA, Marcy-l'Etoile, França) para os bastonetes Gram-negativos e Gram-positivos, anaeróbios obrigatórios/facultativos; 
- API Staph (BioMérieux SA, Marcy-l'Etoile, França) para os estafilococos e micrococos (cocos Gram-positivos, catalase positiva);

- API Strep (BioMérieux SA, Marcy-l'Etoile, França) para os estreptococos (cocos Gram-positivos, catalase negativa);

- API AUX (BioMérieux SA, Marcy-l'Etoile, França) para identificar espécies de Candida.

\section{Análise estatística}

Os testes de Kruskal-Wallis e Dunn, com o nível de significância de 5\%, foram utilizados para verificar os grupos que apresentaram maior frequência de contaminação.

\section{Resultados}

Foi verificado o crescimento microbiano em $20 \%$ na coleta inicial realizada imediatamente após a abertura da embalagem do soro fisiológico (G I), 30\% nas amostras obtidas do soro da cuba endodôntica ao início do tratamento (G II), 55\% nas amostras do soro da seringa irrigadora ao início do tratamento (G III), 50\% na coleta final realizada na embalagem que ficou aberta durante todo o tratamento endodôntico (G IV), 90\% na coleta do soro presente na cuba endodôntica ao final do tratamento endodôntico $(\mathrm{G} \mathrm{V})$ e $90 \%$ na coleta do soro presente na seringa irrigadora ao final do tratamento endodôntico $(G$ VI). A análise estatística pelos testes de Kruskal-Wallis e Dunn demonstra contaminação mais frequente nas amostras dos Grupos V e VI em relação aos Grupos I e II $(p<0,05)$ (Fig. 1).

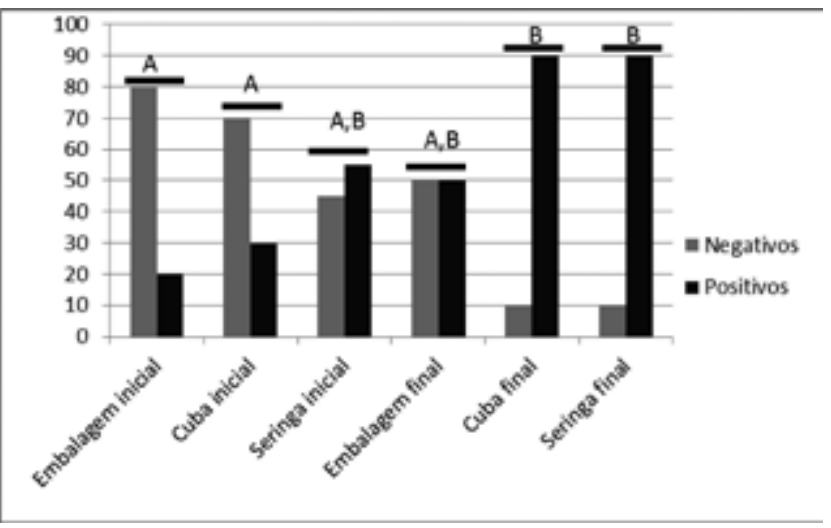

Figura 1 - Frequência de contaminação nas diferentes situações testadas $(n=20)$. Letras diferentes significam diferença estatisticamente significativa em nível de $5 \%$

Staphylococcus spp. foi o microrganismo mais encontrado nas amostras, atingindo uma porcentagem de $79 \%$ (Tab. 1).
Tabela 1 - Porcentagem dos microrganismos encontrados nas amostras de soro fisiológico nas diversas situações testadas

\begin{tabular}{l|c}
\multicolumn{1}{c|}{ Microrganismos } & Porcentagem \\
\hline Staphylococcus epidermidis & $37 \%$ \\
Staphylococcus aureus & $15 \%$ \\
Staphylococcus hominis & $11 \%$ \\
Aerococcus viridans & $11 \%$ \\
Staphylococcus chromogenes & $8 \%$ \\
Staphylococcus xylosus & $8 \%$ \\
Finegoldia magna & $5 \%$ \\
Clostridium sporogenes & $5 \%$ \\
\hline
\end{tabular}

\section{Discussão}

O controle microbiano está intimamente relacionado ao sucesso do tratamento endodôntico ${ }^{12}$. Em situações clínicas, o tratamento endodôntico objetiva a eliminação de microrganismos por meio da associação de preparo biomecânico, irrigação com diferentes soluções e uso de medicação intracanal quando necessária ${ }^{13}$. Como foi observado no presente estudo, o soro fisiológico utilizado na irrigação de canais radiculares não permaneceu estéril durante todo o procedimento endodôntico. Em todas as situações testadas, o irrigante mostrou-se passível de contaminação. Essa contaminação, de acordo com que foi verificado, ocorreu principalmente após o momento em que a embalagem foi aberta, tendo o remanescente de soro na cuba e na seringa, após o tratamento, se mostrado significativamente mais contaminado em relação às amostras obtidas inicialmente no frasco e na cuba.

Apesar de terem sido encontrados vários microrganismos, Staphylococcus spp., um gênero de bactérias muito encontrado na pele, foi observado em maior número, numa porcentagem de 79\%. Delboni ${ }^{14}(2006)$ isolou Staphylococcus spp. em $50 \%$ de canais radiculares com crescimento microbiano de dentes com insucesso do tratamento endodôntico. Tal incidência alerta-nos sobre a necessidade da manutenção da cadeia asséptica durante toda a terapêutica endodôntica, diminuindo, assim, as chances de insucesso.

Dessa forma, fica implícita a necessidade de medidas assépticas, tais como: a) esterilização da cuba endodôntica; b) aquisição de embalagens de soros fisiológicos estéreis, em pequenas quantidades (250 $\mathrm{mL}$ ), com tampa, para que a embalagem seja mantida fechada durante o procedimento; c) abertura da embalagem apenas no momento de seu uso; d) descarte do soro fisiológico da cuba e da embalagem 
após a finalização do tratamento (para evitar o reaproveitamento); e) desinfecção das seringas irrigadoras com gaze estéril embebida em um agente de desinfecção (ex. clorexidina $2 \%$ ) antes do seu preenchimento, para que seja evitada a contaminação do soro fisiológico contido na cuba endodôntica.

A possibilidade de utilizar um irrigante com propriedades antimicrobianas, como a clorexidina $2 \%$ líquida, por exemplo, não deve ser descartada. Entretanto, além do custo elevado, comparado com o do soro fisiológico, outras implicações, tais como reações químicas entre as substâncias químicas auxiliares e esse irrigante, podem ocorrer ${ }^{9,15}$.

\section{Conclusão}

O soro fisiológico pode ser contaminado durante o seu uso na prática endodôntica.

\section{Agradecimentos}

Este trabalho teve o apoio do CNPq (302575/ 2009-0) e da Capes.

\section{Abstract}

Objective: to analyze the contamination of sterile saline solution (SS) used as irrigant substance in endodontic treatment (ET). Materials and method: samples of $1 \mathrm{~mL}$ of $S S$ were collected in Eppendorf-type tubes. Twenty microbiological samples were collected in 6 different situations, as follows: Group I (G I) - soon after the opening of the SS packing; Group II (G II) - after pouring the SS in the endodontic bowl; Group III (G III) - at the moment of the first filling of the irrigating syringe; Group IV (GIV) - from the SS still inside the packing to the end of the treatment; Group $V(G V)$ - from the remaining SS in the endodontic bowl after ET; Group VI (G VI) - from the irrigating syringe to the end of ET. One hundred and twenty samples were processed, incubated, and colonies were identified by means of biochemical tests. Microbial growth was verified in $20 \%$ of the samples collected from G I; $30 \%$ from G II; $55 \%$ from G III; $50 \%$ from G IV; $90 \%$ from $G \mathrm{~V}$, and $90 \%$ from $G$ VI. Results: the statistical analysis performed by the Kruskal-Wallis and Dunn tests showed most frequent contamination for Groups V and VI in relation to Groups I and II $(p<0.05)$. The most frequently found microorganism was Staphylococcus spp., with $79 \%$. Conclusion: it was concluded that the sterile saline solution may be contaminated during its use in endodontic treatment.

Keywords: Removal of contaminants. Microbiology. Endodontics.

\section{Referências}

1. Byström A, Sundqvist G. Bacteriologic evaluation of the effect of 0.5 percent sodium hypochlorite in endodontic therapy. Oral Surg Oral Med Oral Pathol 1983; 55(3):307-12.
2. Byström A, Sundqvist G. Bacteriologic evaluation of the efficacy of mechanical root canal instrumentation in endodontic therapy. Scand J Dent Res 1981; 89(4):321-8.

3. Ferraz CC, Gomes BP, Zaia AA, Teixeira FB, Souza-Filho FJ. Comparative study of the antimicrobial efficacy of chlorhexidine gel, chlorhexidine solution and sodium hypochlorite as endodontic irrigants. Braz Dent J 2007; 18(4): 294-8.

4. Lopes HP, Siqueira Junior JF. Endodontia, biologia e técnica. 3. ed. Rio de Janeiro: Guanabara Koogan; 2010.

5. Torabinejad M, Walton RE. Endodontia: princípios e prática. 4. ed. Rio de Janeiro: Elsevier; 2010.

6. Goldman LB, Goldman M, Kronman JH, Lin PS. The efficacy of several irrigating solutions for endodontics: a scanning electron microscopic study. Oral Surg Oral Med Oral Pathol 1981; 52(2):197-204.

7. Ferraz CC, Gomes BP, Zaia AA, Teixeira FB, Souza-Filho FJ. In vitro assessment of the antimicrobial action and the mechanical ability of chlorhexidine gel as an endodontic irrigant. J Endod 2001; 27(7):452-5.

8. Gomes BP, Souza SF, Ferraz CC, Teixeira FB, Zaia AA, Valdrighi L, et al. Effectiveness of $2 \%$ chlorhexidine gel and calcium hydroxide against Enterococcus faecalis in bovine root dentine in vitro. Int Endod J 2003; 36(4):267-75.

9. Gomes BP, Vianna ME, Zaia AA, Almeida JF, Souza-Filho FJ, Ferraz CC. Chlorhexidine in endodontics. Braz Dent J. 2013; 24(2):89-102.

10. Berber VB, Gomes BPFA, Sena NT, Vianna ME, Ferraz CCR, Zaia AA, et al. Efficacy of various concentrations of $\mathrm{NaOCl}$ and instrumentation techniques in reducing Enterococcus faecalis within root canals and dentinal tubules. Int Endod J 2006; 39(1):10-7.

11. Martinho FC, Chiesa WM, Marinho AC, Zaia AA, Ferraz CCR, Almeida JFA, et al. Clinical investigation of the efficacy of chemomechanical preparation with rotary nickel-titanium files for removal of endotoxin from primarily infected root canals. J Endod 2010; 36(11):1766-9.

12. Kakehashi S, Stanley HR, Fitzgerald RJ. The effects of surgical exposures of dental pulps in germ-free and conventional laboratory rats. Oral Surg Oral Med Oral Pathol 1965; 20:340-9.

13. Estrela CR, Estrela C, Reis C, Bammann LL, Pécora JD. Control of microorganisms in vitro by endodontic irrigants. Braz Dent J 2003; 14(3):187-92.

14. Delboni MG. Identificação de microrganismos presentes na saliva, na coroa e no canal radicular de dentes associados ao insucesso endodôntico e suscetibilidade antimicrobiana de Enterococcus faecalis isolados dos canais radiculares [Dissertação de Mestrado]. Piracicaba: Faculdade de Odontologia de Piracicaba da Universidade Estadual de Campinas; 2006.

15. Vivacqua-Gomes N, Ferraz CC, Gomes BP, Zaia AA, Teixeira FB, Souza-Filho FJ. Influence of irrigants on the coronal microleakage of laterally condensed gutta-percha root fillings. Int Endod J 2002; 35(9):791-5.

\section{Endereço para correspondência:}

Brenda P. F. A. Gomes

Departamento de Odontologia Restauradora - Área de Endodontia

Faculdade de Odontologia de Piracicaba - FOP/Unicamp Av. Limeira, 901 - Bairro Areião

13.414-018 Piracicaba - SP

Fone/Fax: 19 2106-5343, 19 2106-5218

E-mail: bpgomes@fop.unicamp.br

Recebido: 03/07/2013. Aceito: 28/10/2013. 